\title{
A PRÁTICA PEDAGÓGICA EM ARTE - A LEITURA DA IMAGEM NO INICIO DO PROCESSO DE ALFABETIZAÇÃO
}

\author{
Rosangela Maria Gonçalves Val, Helena Faria de Barros \\ Universidade do Oeste Paulista - UNOESTE, Mestrado em Educação, Presidente Prudente, SP. e-mail: \\ rosangela_mgval@hotmail.com
}

\begin{abstract}
RESUMO
Este artigo tem por objetivo analisar a leitura da imagem trabalhada pelos professores de arte em sua prática pedagógica no Ensino Fundamental para suporte à alfabetização. Consiste num estudo de caso com abordagem qualitativa que apreende a subjetividade, os significados expressivos, os sentimentos, a percepção e conceituação dos professores de arte e titulares da sala de aula, em três escolas do Ensino Fundamental. Os procedimentos para a coleta de dados foram observação, entrevista e análise documental e organizados segundo Bardin (2009) em: pré-análise, exploração do material e tratamento dos resultados, inferência e interpretação. A observação utilizada cumpriu um roteiro, do mesmo modo que a entrevista. Atividades significativas desenvolvidas pelos alunos foram também recolhidas para estudo, análise e registro. Constatou-se que a arte, por meio da leitura da imagem, utilizada no inicio da alfabetização, representa importante apoio à aprendizagem.

Palavras-chave: Ensino da Arte, Leitura de Imagem, Práticas Pedagógicas, Alfabetização, Estudo de Caso.

\section{THE PEDAgOgICAL PRACTICE IN ART - READING the IMAge AT the BEgINNING OF the LITERACY PROCESS}

\begin{abstract}
This article aims to analyze the reading of the image crafted by art teachers in their teaching in elementary school, to support the literacy. It consists of a case study with a qualitative approach that grasps subjectivity, expressive meanings, feelings, the perception and conceptualization of art teachers and holders of the classroom, in three schools in the elementary school. The procedures for data collection were observation, interview and documentary analysis and organized according to Bardin (2009): Pre-analysis, material exploration and processing of the results, inference and interpretation. The observation used will follow a script, just as the interview. Significant activities undertaken by the students were also collected for study, analysis and registration. It was found that art, through the reading of the image, used in early literacy, is important to support learning. Keywords: Teaching of Art, Image Reading, Teaching Practices, Literacy, Case Study.
\end{abstract}




\section{INTRODUÇÃO}

As imagens são o veiculo de expressão e comunicação humana desde a pré-história ao presente, constitui uma forma de comunicação que adquiriu dimensões extraordinárias, e permeia a vida cotidiana com mensagens visuais que norteiam a organização da atividade humana em sociedade, embora a "relação entre o que vemos e o que sabemos nunca fica realmente estabelecida por que há um distanciamento presente entre as palavras e o que se vê" (BERGER, 1999, p. 9). Esse "olhar" precede as palavras e sempre fará parte da natureza humana procurar estabelecer uma relação entre o que vemos e o que sabemos.

Essas imagens constituem signos referindo-se às representações e associações que o homem faz em sua vida cotidiana. São relações alimentadas pela capacidade de simbolizar objetos, fatos, acontecimentos que se apropriam de elementos da própria linguagem verbal. Esse modo de representação, visto como prática humana está presente no sistema social, econômico e cultural e revela o contexto cultural pessoal.

Esse contexto cultural, complexo, com muitas variáveis dentro de um tempo e espaço históricos, refere-se a um processo de construção criativo, teórico, técnico, pessoal e social. A necessidade de comunicação rápida e melhor levou o homem a se habilitar a partir da linguagem pictórica que suprimisse o diálogo extenso em que signos e símbolos representariam ideias. Essa representação, no entanto perpassa a aprendizagem cognitiva e aborda a interdisciplinaridade na educação reconhecendo a importância da disciplina de arte na promoção de intervenções e decodificação dos símbolos. Decodificação como leitura da imagem. Para Smeets (1982, p.14-15):

signo em definição
encontra-se como sendo o
gesto ou forma gráfica que
indicam um certo conteúdo,
pensamento ou coisa. O
símbolo é um signo,
marcação ou emblema que
exprima significado
impossível de ser inferido
diretamente do signo,
porém reconhecível pelos
que já tiverem aprendido.

Nesta definição compreendem-se o signo como representações pictóricas que traduzem uma mensagem de fácil compreensão. O símbolo encontra-se internalizado nas práticas humanas, pois faz parte dos processos sociais e históricos das relações humanas. Assim, signos são símbolos e representam ideias como códigos visuais.

A leitura implica a existência de um leitor e de um código e, sendo a imagem um signo do código visual, pode ser interpretada, relacionando-se o objeto e a palavra ao que se refere à imagem, representada pelo texto. 
Segundo Pillar (2011, p.8) "a leitura da imagem é a leitura de um texto com formas, cores, textura e volumes". Ler é atribuir significados que depende do contexto cultural e habilidades do leitor observador.

A palavra de Paulo Freire encontrou destaque em Pillar (2011) quando acrescenta que "aprender a ler, a escrever, alfabetizar-se é, antes de qualquer coisa, aprender a ler o mundo,..."; é que "a leitura do mundo precede a leitura da palavra,..." (PILLAR, 2011, p. 8). Ler a imagem seria perceber, identificar e interpretar os elementos que a compõem atribuindo- the significados próprios e contextuais, mas a partir da visão do autor que também significou a sua imagem. Segundo Martins:

Quando começamos a organizar os conhecimentos adquiridos, a partir das situações que a realidade impõe e da nossa atuação nela; quando começamos a estabelecer relações entre as experiências e a tentar resolver problemas que se nos apresentam - aí então estamos procedendo leituras, as quais nos habilitam basicamente a ler tudo e qualquer coisa. (MARTINS, 2005, p. 17).

A experiência visual é importante no processo de alfabetização não só por compreender a imagem como o mais antigo registro da história humana, relatando a necessidade de comunicação por meio de códigos e signos, como também pelo desenvolvimento sócio-cognitivo e emocional do leitor. Para Achugar (1997), “a transformação tecnológica do presente apenas acelerou processos em curso há muito tempo" (ACHUGAR, 1997, p.07).

Assim, é na leitura da imagem que a pesquisa concentrou seu interesse tendo como motivo o problema comum da escassez imagética na unidade escolar que contribui para o analfabetismo visual e também na ação de como o professor especialista das séries iniciais aplica sua prática pedagógica, trabalhando para reduzir esse comportamento, tendo a Arte como componente curricular de apoio. Observando que alfabetismo visual implica certo nível de universalidade e compreensão e que não será encontrado nas séries iniciais do processo de alfabetização, entende-se, nesta pesquisa, como alfabetismo visual a ampliação imagética que a prática pedagógica em arte pode propiciar ao educando quanto ao seu contato permanente e efetivo com imagens.

Esta questão levou a definir o problema: analisar a aplicabilidade de leitura de imagem trabalhada pelo professor de arte em sua prática pedagógica para propiciar um suporte à alfabetização no Ensino Fundamental. A pesquisa também considera relevante observar a orientação do olhar do aluno e de que modo o 
professor o torna perceptivo. A análise da prática pedagógica com relação à imagem partiu do princípio de que a alfabetização vai além de decifrar o texto escrito. $\mathrm{O}$ artigo, ao explorar sobre a leitura da imagem na alfabetização, pretende destacar relevâncias que contribuam para ampliação do conhecimento. Segundo Pescuma (2005, p.25), há diversos tipos de relevância, e neste artigo, destacou-se as de "caráter acadêmico, profissional e social".

Como relevância acadêmica esperase que a pesquisa possa instigar a reflexão sobre as formas alternativas de alfabetizar com o uso de leitura de imagens. Como relevância profissional, a pesquisa pode oferecer subsídios aos professores de arte a uma prática de atividade artística significativa para o aluno e de apoio à alfabetização mais dinâmica e compreensiva, com emprego de procedimentos de leitura de imagem significativos. Na relevância social espera-se para os alunos situações de uma aprendizagem viva, significativa e com alegria.

Este artigo apresenta como objetivo da pesquisa analisar a aplicabilidade de leitura de imagem trabalhada pelo professor de arte em sua prática pedagógica ao oferecer suporte à alfabetização no Ensino Fundamental, complementando com objetivos específicos que são: analisar os trabalhos realizados em classe pelos alunos sobre a leitura da imagem; identificar por meio da observação e análise dos dados as competências adquiridas pelos alunos, por meio da leitura de imagens e na entrevista avaliar a importância do ensino da arte nas séries iniciais, atribuída pelos professores, o significado da leitura de imagens na alfabetização e o sentido da arte na formação do aluno.

\section{METODOLOGIA}

Optou-se neste trabalho pela abordagem qualitativa, hermenêutica, descritivo-interpretativa por um estudo de caso, tendo como referência "Análise de conteúdo" (BARDIN, 2009). A pesquisa qualitativa é vista como uma realidade construída por meio das definições individuais ou coletivas que estão presentes nas relações sociais e diversidade cultural. Definida a área geográfica, as unidades escolares e os participantes da pesquisa, por meio da coleta de dados, na observação, entrevista e análise documental, a investigação procurou pesquisar ações norteadoras da seleção e apresentação de conteúdos e atividades voltados para a leitura da imagem de modo a identificar nas estruturas educacionais os conteúdos curriculares que justifiquem estas ações. Buscaram-se informações e estas foram organizadas segundo Bardin (2009) em: pré- 
análise, exploração do material e tratamento dos resultados, inferência e sistematização.

\section{O PROCESSO}

Na coleta de dados para a análise documental encontrou-se uma estruturação por parte da Secretaria da Educação do Estado de São Paulo em orientar a prática do professor e em promover uma sequência lógica de atividades que vão complementando a aprendizagem que $\mathrm{o}$ aluno recebe no primeiro ano (10 ano do Ensino Fundamental), que se encontra sob a Administração Municipal. Estes primeiros anos estão sendo trabalhados nas Escolas Municipais de Educação Infantil (os alunos têm seis (6) anos de idade).

É considerada prioridade a competência leitora e escritora do aluno, bem como leitura e produção de textos nas linguagens não verbais, matéria prima do universo da arte (SÃO PAULO (ESTADO). SECRETARIA DE EDUCAÇÃO, 2013, p. 16). Ferreiro (1989) se refere aos processos de aquisição da representação escrita da linguagem:

Alfabetização se refere à aquisição de representação escrita de uma linguagem, ou seja, aquisição simultânea do sistema de representação por escrito de signos e símbolos enquanto objeto do conhecimento (FERREIRO, 1989, p. 7-8).
Segundo Ferreiro (1989), a alfabetização ocorre quando o individuo estabelece que as partes formem um todo e que essa "alfabetização ocorre, sem dúvida, em um ambiente social" (FERREIRO, 1989, p. 24). As informações e práticas sociais do cotidiano têm seu conteúdo transformado na tentativa de compreendê-lo, acrescentando a este sua própria interpretação.

Com base nesta teoria, o professor faz a leitura do texto imagético para os alunos, realiza o levantamento de conhecimentos prévios na roda inicial, informa-os do que vai ser realizado, faz a leitura da obra imagética, distribui o material e assim se inicia a ação criativa. Este mesmo professor no inicio do ano estrutura o caderno do aluno como referência de suas aulas, apresentando textos e estimulando que o aluno escreva.

Segundo Pillar (2011, p.13), “os trabalhos de expressão plástica não são apenas impressões que a criança deixa sobre um material, mas, sobretudo evidenciam o seu estágio de elaboração mental". O que Pillar (2011) explicita é que o nível de desenvolvimento intelectual, emocional e perceptivo se revela nas produções dos alunos e dependem do estimulo recebido e de seu contexto cultural. A mesma relação é defendida por Martins (2005) quando estabelece níveis de compreensão da leitura em sensorial, emocional e racional pelos 
quais o leitor passa a dar sentido às coisas, cria expectativas e amplia as relações que faz com o contexto, desenvolvendo sua própria aprendizagem.

Mesmo considerando que ser professor não é fácil, os profissionais da educação iniciaram sua profissão inspirados em mestres por quem guardam boas lembranças. Consideram estarem aptos a exercer a profissão e que a arte como área do conhecimento é muito importante no currículo dos anos iniciais. Estes professores aplicam o conteúdo das São Paulo (Estado), Secretaria De Educação (2013) e procuram manter a sequência das atividades para que o aluno não tenha um desempenho ruim por rupturas no conteúdo.

E o mais importante é a sequência das proposições, pois segundo Pillar (2011, p.27):

É preciso salientar, ainda, que a vivência de um processo não se resume à experimentação de materiais variados pelo professor. Isto, por si só, não desencadeia processo algum. Desenvolver um processo implica na continuidade de um trabalho, importante e necessário para quem o faz.

Durante a observação, os professores trabalharam atividades diferentes, pois cada unidade escolar se encontrava em uma proposição. Proposições são as situações de aprendizagem apresentadas como sequência didática nas São Paulo (Estado), Secretaria De Educação (2013), para nortear o trabalho do professor em sala de aula. O conteúdo estava adequado, mas a contextualização teve como foco apenas o produto final. Houve levantamento de conhecimentos prévios e retomada de conteúdos anteriores. As práticas pedagógicas foram observadas nas salas em que os alunos já se encontravam em nível alfabético, mas com problemas de estruturação no texto o que é normal pela faixa etária (7anos). Estes alunos, com a orientação do professor, elaboram e organizam representações no espaço proporcionais, isto porque já compreendem o sistema de leitura e escrita.

\section{ALGUMAS CONSIDERAÇÕES}

A observação revelou que os professores buscam atualizar seus conteúdos e mesmo com as São Paulo (Estado), Secretaria De Educação (2013), a inserção de imagens significativas de obras de arte e do cotidiano do aluno ainda é insuficiente.

A contextualização é pobre e tendo como foco apenas o produto final, estes professores não tornam a atividade significativa para o aluno. Os objetivos da atividade são explicados, mas não conseguem desenvolver em $100 \%$ dos alunos/sala de aula, as habilidades propostas 
nos objetivos por utilizarem recursos insuficientes para a visualização.

A avaliação que deveria ser em processo tem foco apenas no produto final e disciplina. No entanto a devolutiva da situação de aprendizagem é adequada em fazer uma retomada de conteúdos, na tentativa de recuperar as habilidades aprendidas e esquecidas para se iniciar uma nova proposição. A socialização de estratégias também é adequada, considerando a faixa etária dos alunos e o seu nível de aprendizagem.

Portanto, considerando os objetivos da pesquisa, este estudo de caso conclui que a prática da leitura de imagem na aula de arte é parte importante e fundamental no processo de alfabetização. Nos dados obtidos, observou-se que nas estruturas educacionais há conteúdos curriculares que contribuem e orientam professores, para desenvolverem boas práticas pedagógicas nas aulas de arte. A contribuição da disciplina de arte para a alfabetização é ímpar nesse processo e as habilidades que são estimuladas desenvolvem as competências, entre muitas, de explorar, perceber, expressar-se, realizar, reconhecer, associar.

\section{REFERÊNCIAS}

ACHUGAR, H. Imagens da integração. São Paulo: Fundação Memorial da América Latina, 1997. Coleção MeMo: Ensaio/ficção.
BANKS, M. Dados visuais para a pesquisa qualitativa. Porto Alegre: Artmed, 2009.

BARDIN, L. Análise de conteúdo. Lisboa: Edições 70, 2009.

BERGER, John. Modos de ver. Rio de Janeiro: Rocco, 1999.

FERREIRO, E. Alfabetização em processo. São Paulo: Cortez: Autores Associados, 1989.

MARTINS, M. H. O que é leitura. São Paulo: Brasiliense, 1984. In: PESCUMA, D. Projeto de Pesquisa - o que é? Como fazer?: um guia para sua elaboração. São Paulo: Olho d'Água, 2005.

PESCUMA, Derna; CASTILHO, Antonio Paulo Ferreira de. Projeto de pesquisa. O que é? Como fazer? Um guia para sua elaboração. São Paulo: Olho d'Água, 2005.

PILLAR, A. D. (org.). A educação do olhar no ensino das artes. Porto Alegre: Mediação, 2011.

SÃO PAULO (Estado). Secretaria da Educação do Estado de São Paulo. Coordenadoria de Gestão da Educação Básica. Orientações curriculares e didáticas de arte para o ensino fundamental - anos iniciais. São Paulo: SEE, 2013.

SMEETS, R. Signos, símbolos e ornamentos. São Paulo: Ediouro, 1982.

Recebido para publicação em 11/08/2014 Revisado em 15/09/2014

Aceito em 18/09/2014 